\title{
Qinhuangdao City Tourism Risk Warning and Release
}

\author{
Chengyu Yan ${ }^{1}$ Guohua Zhang ${ }^{2}$ Fene Cui ${ }^{1} \quad{\text { Yang } \mathrm{Li}^{1}}^{\mathrm{Jie} \mathrm{Wu}}{ }^{1}$ \\ 1. Qinhuangdao City Meteorological Bureau, Qinhuangdao 066000, China \\ 2. Hebei Weather Observatory,Shijiazhuang 050021,China \\ 秦皇岛市旅游风险预警与发布 \\ 燕成玉 ${ }^{1}$ 张国华 ${ }^{2}$ 崔粉娥 ${ }^{1}$ 李旸 ${ }^{1}$ 吴杰 ${ }^{1}$ \\ 1. 河北省秦皇岛市气象局, 秦皇岛 066000 , 中国 \\ 2 河北省气象台, 石家庄050021, 中国
}

\begin{abstract}
Using the meteorological data of Qinhuangdao City from 2001 to 2015, the weather of thunderstorms and hail are counted. Summarize the relevant parameter thresholds for different types of severe convective weather. The Qinhuangdao tourism meteorological service platform will be constructed to transmit early warning information to tourists through SMS, street electronic display, and real-time broadcasting in scenic spots. Effective communication channels avoid the travel risks for the majority of tourists, making the journey comfortable and complete.
\end{abstract}

Keywords-tourism risk, communication route, disaster warning, Qinhuangdao

摘要一用秦皇岛市 2001-2015 年 15a 的气象资料, 统计出 雷雨大风、冰雹日期。总结不同类型强对流天气发生的相关参 数阈值。构建秦皇岛旅游气象业务服务平台, 通过手机短信、 街头电子显示屏、景区实时广播等途径向游客传递预警信息。 有效的沟通途径为广大游客规避了旅游风险, 使旅途舒适而圆 满。

关键词：旅游风险，沟通途径，灾害预警，秦皇岛

$$
\text { I.引言 }
$$

改革开放 40 年来，依托良好的生态环境和区位优势， 秦皇岛市旅游业迅速发展，成为河北省旅游龙头城市并被

作者简介: 燕成玉 (1970-), 女, 汉族, 河北秦皇岛人, 高级 工程师，主要从事旅游气象服务、天气预报及技术方法研究。 E-mail: 1075594512@qq.com 通讯作者: 张国华 (1963-), 女, 汉族, 河北石家庄人，正高 级工程师, 主要从事旅游气象预报、服务和科研工作。E-mail: gzgh2308@163.com
省委省政府确定为全省唯一"旅游立市"城市, 秦皇岛市自 然景观颇多, 滨海度假和山地生态旅游发达, 然秦皇岛区 域地形地貌复杂, 强对流天气 ${ }^{[1-5]}$ 发生频率较高, 强对流 天气具有突发性强, 局地性强, 瞬时天气剧烈的特性, 不 期而至的雷雨大风、冰雹等给游客带来一定的旅游风险 [6-8], 准确的天气预报、有效的沟通途径则可为广大游客 规避旅游风险, 使旅途舒适而圆满。

\section{II. 资料和方法}

用秦皇岛区域 5 个国家气象站（图 1）2001-2015 年 $15 \mathrm{a}$ 的地面基站观测资料和灾情资料，统计出雷雨大风、 冰霞日期。将发生以上天气的欧亚区域 08 时（北京时） 高空形势图进行天气学分型, 总结不同类型强对流天气发 生的相关参数阈值。构建秦皇岛旅游气象业务服务平台, 通过手机短信、街头电子显示屏、景区实时广播等途径向 游客传递预警信息。

\section{III..结果和分析}

\section{1 秦皇岛区域灾害天气分型及预报指标}

\section{1 .1 雷雨大风}

秦皇岛雷雨大风集中出现 4-9 月, 时段主要集中在午 后到前半夜。 15 年间共出现雷雨大风 49 次，其中高空冷 浴型 20 次, 其次为阶梯槽型 12 次, 低槽冷锋型 10 次, 西北气流型 7 次。表 1 给出了雷雨大风的天气分型、各型 占比及指标阈值, 图 2 给出了雷雨大风环流示意图。 


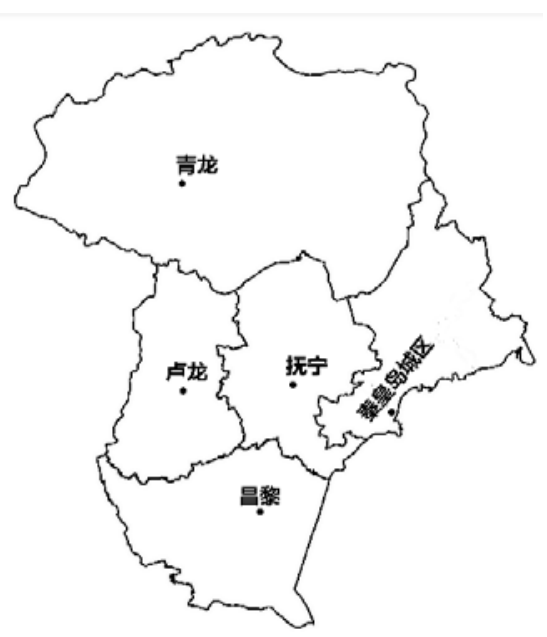

图 1 秦皇岛区域气象观测站分布图

Figure 1 Distribution of counties and districts in Qinhuangdao

表 1.秦皇岛区域雷雨大风天气分型及指标阈值

Table 1. Thunderstorm and gale weather classification and index threshold in Qinhuangdao area

\begin{tabular}{|c|c|c|c|c|}
\hline 分型 & 高空冷浴型(图 2a) & 阶梯槽型(图 2b) & 低槽冷锋型(图 2c) & 西北气流型(图 2d) \\
\hline 各型占比 & $41 \%$ & $24 \%$ & $20 \%$ & $14 \%$ \\
\hline 各型特征 & $\begin{array}{l}500 \mathrm{hPa} \text { 蒙古国附近 } \\
\text { 或东北地区有一低 } \\
\text { 浴, 低浴底部有大于 } \\
20 \mathrm{~m} / \mathrm{s} \text { 的西风或西北 } \\
\text { 风; } 850 \mathrm{hPa} \text { 相似位置 } \\
\text { 有一低浴; 地面为低 } \\
\text { 压控制有冷锋过境; } \\
\mathrm{T} \text { logp 图上近地面有 } \\
\text { 喇叭口形状, 中低层 } \\
\text { 有湿区或亚湿区。 }\end{array}$ & $\begin{array}{l}500 \mathrm{hPa} \text { 有阶梯槽, 一 } \\
\text { 个在河套附近, 一个 } \\
\text { 在贝湖附近, 且秦皇 } \\
\text { 岛上游有大于 } 24 \mathrm{~m} / \mathrm{s} \\
\text { 的西北风的高空急 } \\
\text { 流; } 850 \mathrm{hPa} \text { 相似位置 } \\
\text { 为一横槽; } \mathrm{T} \text { logp 图 } \\
\text { 上 } 925 \mathrm{hPa} \text { 以下有逆 } \\
\text { 温层, } 600 \mathrm{hPa} \text { 左右 } \\
\text { 有少量湿区, 整层大 } \\
\text { 气较干燥。 }\end{array}$ & $\begin{array}{l}500 \mathrm{hPa} \text { 华北地区有 } \\
\text { 一宽槽或河套地区有 } \\
\text { 一低涡, 秦皇岛上游 } \\
\text { 有达到 } 36 \mathrm{~m} / \mathrm{s} \text { 的西北 } \\
\text { 风高空急流; } 850 \mathrm{hPa} \\
\text { 有 } 18 \mathrm{~m} / \mathrm{s} \text { 的西北风低 } \\
\text { 空急流, 且有高于 } \\
12^{\circ} \mathrm{C} \text { 的温度脊。地面 } \\
\text { 为低压冷锋; } \mathrm{T} \_l o g p \\
\text { 图上中层 } 800 \mathrm{hPa} \text { 到 } \\
500 \mathrm{hPa} \text { 湿度较大。 }\end{array}$ & $\begin{array}{l}500 \mathrm{hPa} \text { 秦皇岛区位 } \\
\text { 于槽后西北气流中, } \\
\text { 风速大于 } 20 \mathrm{~m} / \mathrm{s} \text {, 午 } \\
\text { 后有冷空气摆下; 地 } \\
\text { 面有辐合线; } \mathrm{T} \_l o g p \\
\text { 图上 } \mathrm{CAPE} \text { 值较大, } \\
\text { 一般大于 } 1000 \mathrm{~J} / \mathrm{kg} \text {, } \\
700 \mathrm{hPa} \text { 以下有湿区。 }\end{array}$ \\
\hline $850 \mathrm{hPa}$ 比湿 $(\mathrm{g} / \mathrm{kg})$ & $3-13$ & $3-15$ & $3-12$ & $1-10$ \\
\hline $\mathrm{K}$ 指数 $\left({ }^{\circ} \mathrm{C}\right)$ & $24-39$ & $19-39$ & $19-35$ & $10-30$ \\
\hline $\mathrm{CAPE}(\mathrm{J} / \mathrm{kg})$ & $0-1700$ & $0-3500$ & $0-1000$ & $0-2000$ \\
\hline $\mathrm{O}^{\circ} \mathrm{C}$ 层高度(距地 $\mathrm{km}$ ) & $3-5$ & $3-5$ & $3-5$ & $2-5$ \\
\hline $\begin{array}{l}-20^{\circ} \mathrm{C} \text { 层高度(距地 } \\
\mathrm{km})\end{array}$ & $6-8$ & $6-8.5$ & $6-8$ & $5-8$ \\
\hline 温度直减率 $\left({ }^{\circ} \mathrm{C} / \mathrm{km}\right)$ & $4-8$ & $5-8$ & $5-9$ & $5-8$ \\
\hline
\end{tabular}

3.1 .2 冰雨

秦皇岛 5 个观测站中有 1 个测站出现冰雨就记为 1 次, 同一日两个测站出现冰雹记为 2 次。2001-2015 年的 15
年间，秦皇岛区域共发生冰雼 27 次，其中高空冷浴型 17 次, 西北气流型和横槽转坚型均 4 次, 前倾槽型 2 次。表 

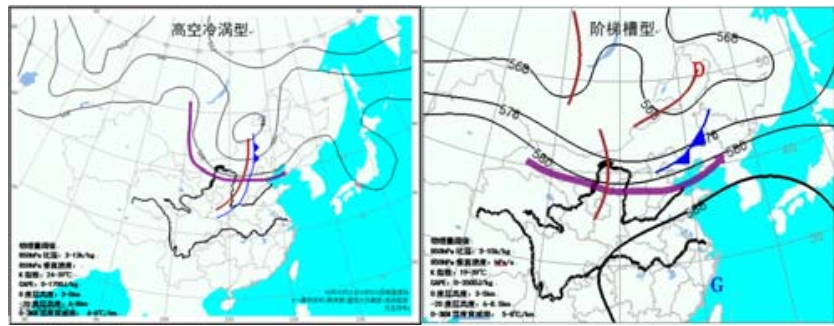

图 2 秦皇岛区域雷雨大风环流示意图及阈值

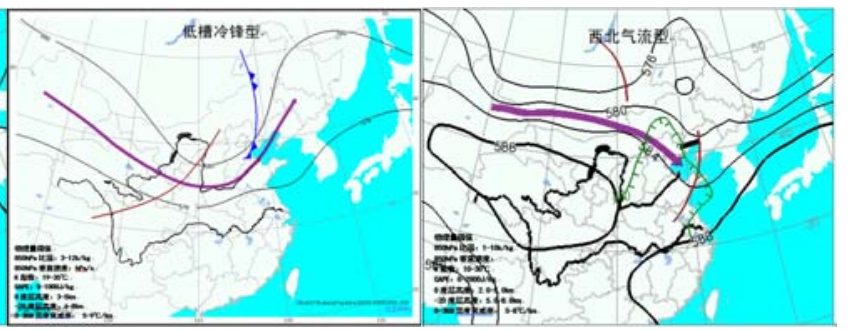

Figure 2 Thunderstorm gale circulation and index threshold in Qinhuangdao Region

表 2. 秦皇岛区域冰雨天气分型及指标阈值

Table 2. Hail weather classification and index threshold in Qinhuangdao area

\begin{tabular}{|c|c|c|c|c|}
\hline 分型 & 高空冷浴型(图 3a) & 西北气流型(图 3b) & 横槽转坚型(图 3c) & 前倾槽型(图 3d) \\
\hline 各型占比 & $63 \%$ & $15 \%$ & $15 \%$ & $7 \%$ \\
\hline \multirow[t]{16}{*}{ 各型特征 } & 此型包含东蒙冷浴、 & 秦皇岛区域位于高 & 秦皇岛位于高空急流 & 秦皇岛区域位于 \\
\hline & 东北冷浴、华北冷浴。 & 空西北急流下方或 & 出口区左侧; $500 \mathrm{hPa}$ & 高空急流出口区 \\
\hline & 秦皇岛位于高空急流 & 高空急流左侧; & 日本海附近（140 & 左侧或高空急流 \\
\hline & 出口区左侧; $500 \mathrm{hPa}$ & 500hPa 槽线位于 & $\mathrm{E}, 45^{\circ} \mathrm{N}$ ) 经常有低 & 下方； 500hPa \\
\hline & 河北省区域北部有闭 & $120^{\circ} \mathrm{E}$ 以东附近, & 浴, 贝湖附近为暖脊, & $\left(116^{\circ} \mathrm{E}, 40^{\circ}\right.$ \\
\hline & 合冷低浴, 由低浴向 & 河北区域受西北气 & 秦皇岛北部 $45^{\circ} \mathrm{N}$ 附 & N) 附近有浅槽, \\
\hline & 南延伸一低槽, 河北 & 流控制, 有大于等 & 近有横槽, 有冷空气 & 槽后有 $16 \mathrm{~m} / \mathrm{s}$ 的 \\
\hline & 被大范围冷温槽控 & 于 $16 \mathrm{~m} / \mathrm{s}$ 的西北风; & 沿脊前西北或偏北气 & 西北风, 贝湖附 \\
\hline & 制; $850 \mathrm{hPa}$ 秦皇岛区 & 副高位置偏东偏 & 流南下影响秦皇岛, & 近有冷中心, 河 \\
\hline & 域位于槽前, 且为暖 & 南; 700hPa 或 & 且风速较大, 达到 & 北省受冷温度槽 \\
\hline & 温度脊; 副热带高压 & $850 \mathrm{hPa}$ 有横槽; & $16 \mathrm{~m} / \mathrm{s} ; 850 \mathrm{hPa}$ 贝湖附 & 控制; 850hPa- \\
\hline & 偏弱; 低层有湿区或 & $850 \mathrm{hPa}$ 或 $925 \mathrm{hPa}$ & 近为暖脊, 秦皇岛低 & $500 \mathrm{hPa}$ 有前倾 \\
\hline & 亚湿区, 中层有干区; & 有暖温度脊; 地面 & 层有湿区或亚湿区, & 槽; 地面为低压 \\
\hline & 地面位于低压带中, & 受弱低压控制, 有 & 中层有干区; 地面位 & 控制, 有风的辐 \\
\hline & 有辐合线, 降雹发生 & 地面辐合线, 冰雹 & 于低压带中, 有地面 & 合, 降雹发生在 \\
\hline & 在辐合线附近。 & $\begin{array}{l}\text { 常常发生在地面辐 } \\
\text { 合线附近。 }\end{array}$ & $\begin{array}{l}\text { 辐合线, 降霖发生在 } \\
\text { 地面辐合线附近。 }\end{array}$ & $\begin{array}{l}\text { 地面辐合线附 } \\
\text { 近。 }\end{array}$ \\
\hline $850 \mathrm{hPa}$ 比湿 $(\mathrm{g} / \mathrm{kg})$ & $4-12$ & $9-10$ & $7-13$ & 个例少略 \\
\hline $\mathrm{K}$ 指数 $\left({ }^{\circ} \mathrm{C}\right)$ & $27-40$ & $28-32$ & $30-34$ & 同上 \\
\hline CAPE $(J / k g)$ & $600-1200$ & $900-1650$ & $500-1575$ & 同上 \\
\hline $\mathrm{O}^{\circ} \mathrm{C}$ 层高度(距地 $\mathrm{km}$ ) & $3-5$ & $3.5-4.5$ & $3-4.5$ & 同上 \\
\hline$-20^{\circ} \mathrm{C}$ 层高度(距地 & $5.5-8 \mathrm{~km}$ & $6-7$ & $6-8$ & 同上 \\
\hline \multicolumn{5}{|l|}{$\mathrm{km})$} \\
\hline $\begin{array}{l}-20^{\circ} \mathrm{C} \text { 与 } \mathrm{O}^{\circ} \mathrm{C} \text { 层之间厚 } \\
\text { 度 }(\mathrm{km})\end{array}$ & $2.8-4.5$ & $2.8-3.5$ & $2.7-3.5$ & 同上 \\
\hline $\begin{array}{l}\text { 850hPa 垂直速度 } \\
(\mathrm{hPa} / \mathrm{s})\end{array}$ & $<-1$ & $<0$ & $<-2$ & 同上 \\
\hline
\end{tabular}



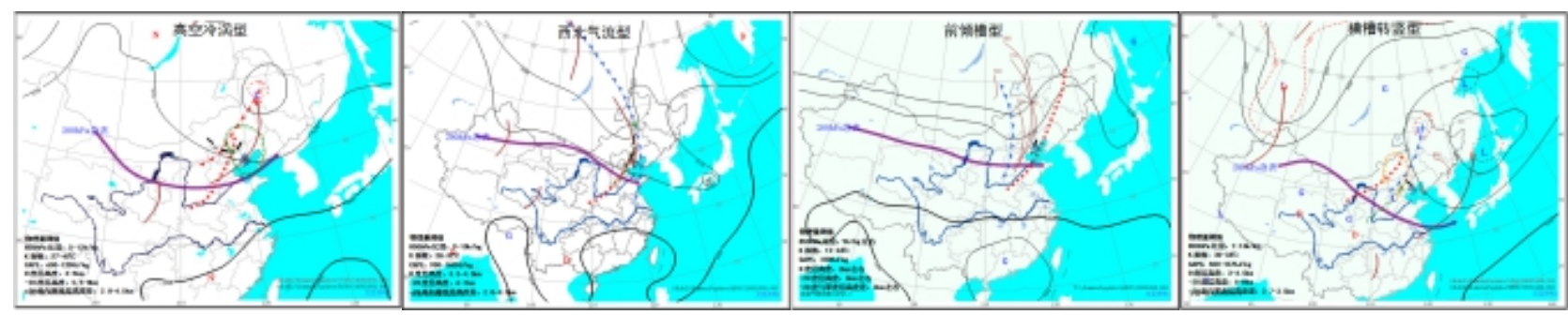

图 3 秦皇岛区域冰雱环流示意图及阈值

Figure 3 Hail circulation and index threshold in Qinhuangdao Region

用 2016 年资料进行检验, 共 6 次强对流天气过程, 灾害天气模型环流形势描述均正确（表 3)。从表 4 分析 发现, 6 月 8 日同时出现雷雨大风、冰雹, 满足 6 个雷雨 大风阈值中的 5 个, 满足 6 个冰雱阈值中的 4 个; 雷雨大 风过程, 各条件满足阈值的正确率高于 $67 \%$ 。从 2016 年 对雷雨大风、冰霄的检验结果表明, 各灾害性天气分型和 阈值在预报中取得了不错的效果, 是可行的。
表 32016 年灾害天气模型检验结果

Table 32016 disaster weather model test results

\begin{tabular}{llcl}
\hline 日期 & 灾害类型 & 环流描述检验 & 环流模型 \\
\hline 2016.6 .8 & 雷雨大风冰雹 & 正确 & 高空冷浴型 \\
2016.6 .10 & 雷雨大风 & 正确 & 高空冷浴型 \\
2016.6 .17 & 雷雨大风 & 正确 & 高空冷浴型 \\
2016.6 .21 & 雷雨大风 & 正确 & 高空冷浴型 \\
2016.6 .24 & 雷雨大风 & 正确 & 西北气流型 \\
2016.8 .25 & 雷雨大风 & 正确 & 高空冷浴 \\
\hline
\end{tabular}

表 42016 年灾害天气模型阈值检验结果

Table 42016 disaster weather model threshold test results

\begin{tabular}{|c|c|c|c|c|c|c|c|c|c|}
\hline \multirow[t]{2}{*}{ 日期 } & $850 \mathrm{hPa}$ & $850 \mathrm{hPa}$ & $850 \mathrm{hPa}$ & $\mathrm{K}$ 指数 & CAPE & $0^{\circ} \mathrm{C}$ 层 & $-20^{\circ} \mathrm{C}$ 层 & \multicolumn{2}{|c|}{$0^{\circ} \mathrm{C}$ 层与 $-20^{\circ} \mathrm{C} \quad 0-3 \mathrm{~km}$} \\
\hline & 比湿 $\mathrm{g} / \mathrm{kg}$ & 垂直速度 $\mathrm{hPa} / \mathrm{s}$ & 温度露点差 ${ }^{\circ} \mathrm{C}$ & ${ }^{\circ} \mathrm{C}$ & $\mathrm{J} / \mathrm{kg}$ & 高度 km & 高度 km & 层高度差 km & 温度直减率 \\
\hline 2016. 6.8 & 4 /正确 & -6.0 /正确 & - & $5 /$ 低 & 4/正确 & 4/正确 & 7/正确 & 3/正确 & 8/正确 \\
\hline 2016. 6.10 & 4/正确 & - & - & $11 /$ 低 & 0/正确 & 5.6/高 & 7/正确 & - & 4/正确 \\
\hline 2016. 6.17 & 6/正确 & - & - & 缺 & 缺 & 4. 0 /正确 & 7.0/正确 & - & 6/正确 \\
\hline 2016.6. 21 & 10/正确 & - & - & 36/正确 & 100/正确 & 4. 5/正确 & 7.6/正确 & - & 5/正确 \\
\hline 2016. 6.24 & 4/正确 & - & - & 15/低 & 519/正确 & 角 5/正确 & 6.5/正确 & - & 缺 \\
\hline 2016. 8. 25 & 11/正确 & - & - & 24/正确 & 0/正确 & 5/正确 & 7/正确 & - & 5/正确 \\
\hline
\end{tabular}

（/是与阈值的对比，“低” 表示低于阈值，“高” 表示高出阈值，一表示不予填写）

\section{2 构建旅游气象业务服务平台}

秦皇岛旅游气象服务系统总体上分为三个子系统: 旅 游气象监测系统、气象服务产品系统、气象服务信息发布 系统。这里只简单介绍气象服务产品系统、气象服务信息 发布系统。

\subsection{1 秦皇岛旅游景区及海上重点区域精细化预报}

选择秦皇岛区域内各大旅游景点及海上重点区域中的 47 个点作为精细化预报的站点, 在程序编写过程中选择
以配置文件的方式进行读取站点位置, 在后期可以根据不 断变化的需要更新或增减站点。

精细化预报选取每日两次的 $\mathrm{EC}$ 细网格预报 $\left(0.125^{\circ}\right.$ $\times 0.125^{\circ}$ 格点）, 对各站点利用双线性内插法进行格点 插值, 然后利用人工预报订正而成。

\section{2 .2 秦皇岛海洋精细化预报预警发布平台}

平台分为海区预警和预警文本两部分。海区预警能够 选择预警的时效, 分别为 1 小时、 2 小时、 6 小时、 12 小 时, 在相应的站点后面勾选需要预警的强对流天气, 点击 保存后自动生成报文（图 4, 图 5)。 
预警文本可以自动读取气象台制作发布的预警信号， 然后根据需要进行修改后保存发送。

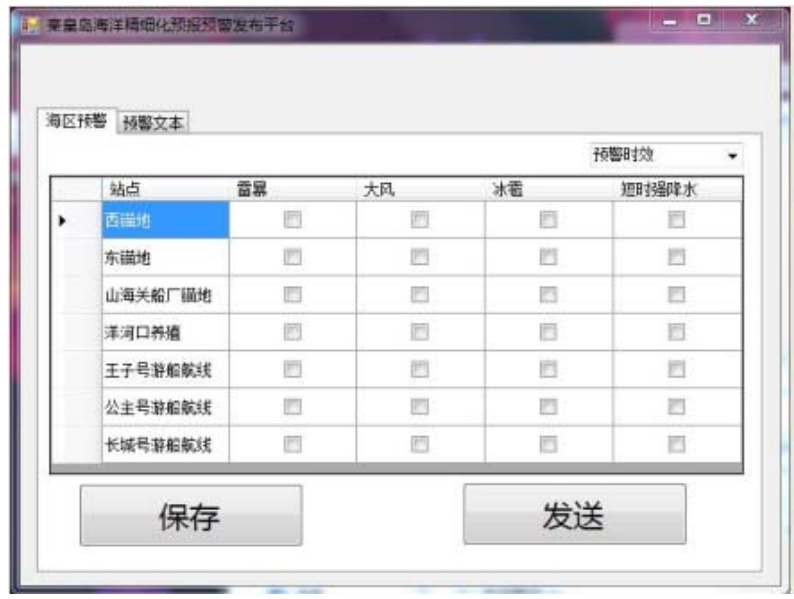

图 4 秦皇岛海洋精细化预报预警发布平台海区预警界面

Figure 4 Qinhuangdao marine refined forecasting and warning release platform sea area early warning interface

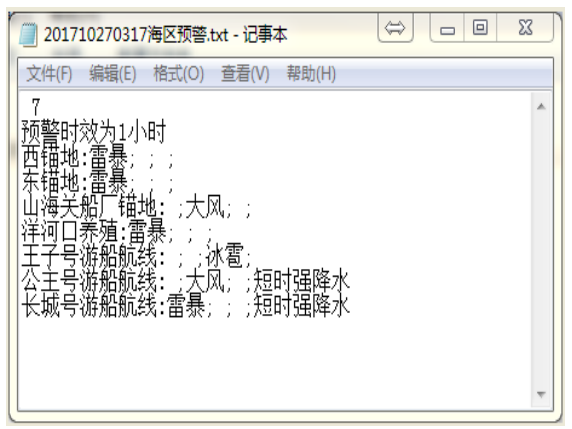

图 5 海区预警报文

Figure5 Sea area pre-alert text

IV.讨论

2016 年 6 月 8 日下午至傍晚受高空冷浴后部的冷空 气影响, 秦皇岛区域出现强对流天气, 部分地区出现短时 大风、冰雹、短历时强降水（图 6)。其中抚宁站 $41.6 \mathrm{~mm}$,

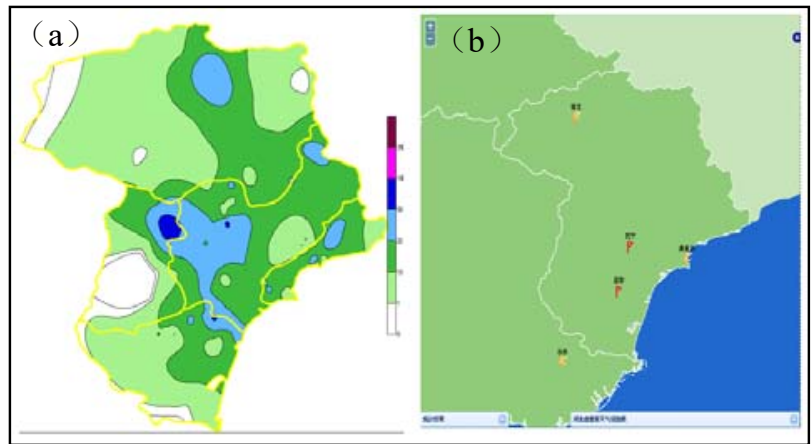

图 62016 年 6 月 8 日 08 时-9 日 08 时 a:秦皇岛市降水分 布图;b:灾害天气实况

Figure 6 08:00 on 8 June-08:00 on 9 June 2016 a: Distribution of precipitation in Qinhuangdao City; b: Disaster weather in Qinhuangdao City

海港区站 $33.4 \mathrm{~mm}$, 卢龙北花台自动监测站 $63.2 \mathrm{~mm}$, 该站 最大小时雨强达 $31.0 \mathrm{~mm} / \mathrm{h}$ 。青龙县东部、昌黎县东北部、 卢龙县北部、山海关区、海港区、抚宁区均出现冰雨, 冰 雹最大直径 $15 \mathrm{~mm}$, 冰雹持续时间约 $20 \mathrm{~min}$ 。抚宁区、昌 黎气象站出现 8 级大风。

在 2016 年 6 月 8 日 08 时 $250 \mathrm{hPa}$ 图上, 秦皇岛位于 高空急流出口区左侧 (图略)，500hPa 高空图上 (图 7a), 欧亚中高纬为两槽一脊型, 在东北地区存在一个深厚的低 浴, 中心值为 $549 \mathrm{gpm}$, 并有 $-23^{\circ} \mathrm{C}$ 的冷中心与之配合, 河 北全省被大范围冷温度槽控制, 秦皇岛位于低浴后部的西 北气流中，有风速 $26 \mathrm{~ms}^{-1}$ 的西北急流。 $700 \mathrm{hPa}$ (图 7b) 及 $850 \mathrm{hPa}$ （图 7c）与 $500 \mathrm{hPa}$ 相对应位置都有低浴存在, $850 \mathrm{hPa}$ 有横切变, 位置偏北, 低层有湿区。 $850 \mathrm{hPa}$ 与 $500 \mathrm{hPa}$ 温差为 $30^{\circ} \mathrm{C}$, 下暖上冷使得层结不稳定, 有利于 8 日下午的降水和强对流天气产生。

从地面形势场看 (图 7d)，8 日 08 时在内蒙古中部 地区存在一气旋, 河北北部存在一辐合线, 秦皇岛位于高 压后部。17 时辐合线南压到秦皇岛北部，触发了这次强 对流天气。

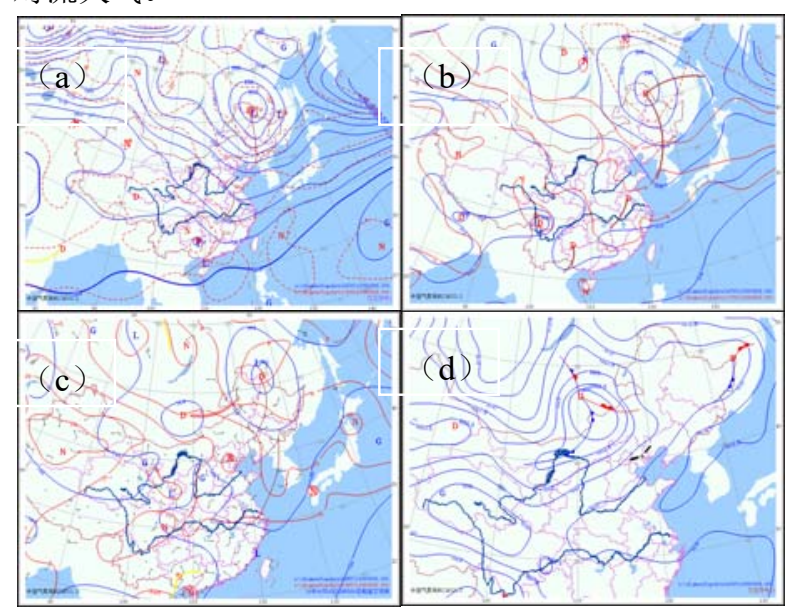

图 72016 年 6 月 8 日实况 a: $500 \mathrm{hPa} ; \mathrm{b}: 700 \mathrm{hPa} ; \mathrm{c}: 850 \mathrm{hPa}$; d:地面

Figure 7 Live map of June 8, 2016 a:500hPa;b:700hPa; c:850hPa;d: ground

由高低空配置图可知（图 8）：秦皇岛位于高空急流 左侧, 冷空气沿低浴后部不断分裂南下影响秦皇岛地区。 秦皇岛位于 “上冷下暖” 的区域, 有一条平行于燕山山脉 
的地面辐合线南压影响我区, 湿区位置偏南, 我市受干线 影响, 有利于产生对流活动。

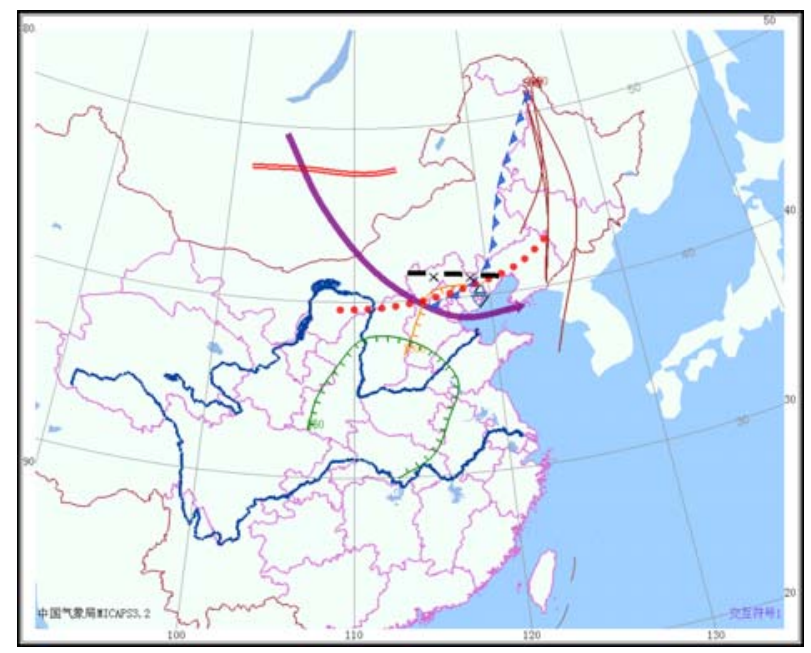

图 82016 年 6 月 8 日 08 时高低空配置图

Figure8 High and low altitude configuration map at 08:00 on June 8, 2016

从 6 月 8 日 08 时乐亭探空曲线（图略）可以看出: 其结构为上干下湿的 “喇叭口” 型, 但 CAPE 值为 $4, K$ 指数数值比较小, 有明显的风速切变, 风向切变不明显。 $0^{\circ} \mathrm{C}$ 层高度为 3583 米, $-20^{\circ} \mathrm{C}$ 层高度为 6613.8 米, $-10^{\circ} \mathrm{C}$ $\sim-30^{\circ} \mathrm{C}$ 层为冰雹的主要增长层, 雷达反射率中心强度大于 $50 \mathrm{dBz}$ 的高度应扩展到 $-20^{\circ} \mathrm{C}$ 以上, 特征高度已满足上述 条件, 这种环境有利于雹胚的生成和发展。14 时订正的 探空, CAPE 值从 08 时的 $4.3 \mathrm{~J} / \mathrm{kg}$ 迅速增加到 $1299 \mathrm{~J} / \mathrm{kg}$, 说明有一定的不稳定能量。 $\mathrm{K}$ 指数仍不太理想。

本次过程 $\mathrm{K}$ 指数未达到阈值, CAPE 值订正后达到阈 值, 其他均达到间值。强对流过程局地性较强, 大尺度环 境场特征有时体现不出来。

所以要警惕低浴形势下, 不稳定指数未达到阈值的雷 雨大风、冰雨天气。

\section{V.结论}

对秦皇岛区域内的灾害天气，据其特征进行分型，总 结不同灾害性天气的物理量阈值, 构建了旅游气象业务服 务平台, 此项业务对即将发生的灾害性天气雷雨大风、冰 雹等通过手机短信、街头电子显示屏、景区实时广播等途 径向游客传递预警信息则可为广大游客规避旅游风险, 使 旅途舒适而圆满。

\section{致谢}

本项目受河北省气象局科研项目 “秦皇岛旅游 气象服务系统”（编号：15ky31）, 河北省科学技 术厅重点研发项目 “重大自然灾害多层级精准救助 关键技术研究”（编号：18275402D）资助。

\section{参考文献}

[1]苏永玲, 何立富, 巩远发等. 京津冀地区强对流时空分布与天气学特 征分析。气象，2011,37(2):177-184.

[2] 翟菁, 周后福, 张建军等. 基于指标叠套法的安徽省强对流天气潜势 预警研究。气象与环境学报, 2011,27(2):1-7.

[3] 郁珍艳, 何立富, 范广洲等. 华北冷浴背景下强对流天气的基本特 征。热带气象学报，2011, 27(2):89-94.

[4] 张小玲, 谌芸, 张涛. 对流天气预报中的环境场条件分析 .气象学 报，2012, 70(4) :6042-54.

[5] 郑媛媛, 姚晨, 郝莹等. 不同类型环流背景下强对流天气短时临近 预报预警研究。气象，2011,37(7):765-801.

[6]宗恬, 黄崇福. 自然灾害风险评估中诸因素之间关系的初探 . 应用 基础与工程科学学报，2004, 12:22-26.

[7]罗奇峰. 都市灾害风险评估中的几个问题. 全国首届灾害风险评估研 讨会论文摘要集，1996。

[8] 庞西否, 黄崇福, 赵思健. 自然灾害风险分析方法与相关技术的研究 进展跟踪. Chinese Perspective on Risk Analysis and Crisis Response（RAC-2010）, 2010, 87-93 